\title{
Análise microclimática de um edifício histórico em clima temperado: limites sustentáveis para a correta conservação dos materiais
}

\author{
Microclimatic analysis of a historic building in temperate \\ climate: target range for the proper conservation of the \\ materials
}

\section{Hugo Entradas Silva \\ Fernando Manuel Anjos Henriques}

\section{Resumo \\ A}

pesar da reconhecida importância conferida ao estudo microclimático em edifícios históricos para a correta conservação de suas coleções e objetos de relevância histórica e cultural, o conhecimento acerca de seu comportamento em climas temperados é ainda reduzido. Ao longo das últimas décadas surgiram diferentes especificações focadas nas necessidades higrotérmicas dos materiais. Nesse campo, a abordagem dinâmica, baseada no microclima histórico, gerou um amplo consenso entre os especialistas, como meio de alcançar intervalos sustentáveis de temperatura e umidade relativa. Este estudo visou classificar de forma clara o microclima interior de um edifício histórico em clima temperado - Igreja de São Cristóvão, em Lisboa -, com o objetivo de verificar a qualidade microclimática para a conservação dos materiais e validar possíveis alterações. Para tal, utilizou-se um sistema de monitoramento continuo entre novembro de 2011 e agosto de 2013, com registros a cada $10 \mathrm{~min}$, utilizando-se diversos sensores de temperatura e umidade relativa. $\mathrm{O}$ microclima foi classificado de acordo com a especificação ASHRAE - Handbook HVAC Applications, Chapter 21: Museums, galleries, archives and libraries. Constatou-se elevada estabilidade climática natural, que não justifica a implementação de sistemas de climatização.

Palavras-chaves: Conservação preventiva. Microclima. Temperatura. Umidade relativa. Edifícios históricos. Inércia térmica.

Hugo Entradas Silva Universidade Nova de Lisboa Caparica - Portugal

Fernando Manuel Anjos Hemriques Universidade Nova de Lisboa Caparica - Portugal

Recebido em 06/03/14 Aceito em 19/02/15

\begin{abstract}
Despite the recognised importance of microclimatic studies in historic buildings for the proper conservation of their collections and of historically and culturally important objects, knowledge about their behaviour in temperate climates is still limited. The past decades have seen the emergence of different specifications focused on the hygrothermal needs of materials. A dynamic approach, based on historical microclimates, has generated consensus among experts as a means to achieve sustainable ranges of temperature and relative humidity. This study aimed to classify the interior microclimate of a historic building in a temperate climateSt. Christopher church, Lisbon-, in order to verify the quality of the microclimate for the proper conservation of materials and to evaluate possible changes. For this purpose, a continuous monitoring system was used between November 2011 and August 2013, with several sensors measuring temperature and relative humidity recording every 10 minutes. The microclimate was classified in accordance with an ASHRAE specification - Handbook HVAC Applications, Chapter 21:

Museums, galleries, archives and libraries. The high natural climatic stability verified does not justify the implementation of HVAC systems.
\end{abstract}

Keywords: Preventive conservation. Microclimate. Temperature. Relative humidity. Cultural heritage. Thermal inertia. abr./jun. 2015. 


\section{Introdução}

\section{Evolução da análise microclimática em edifícios históricos}

A conservação do patrimônio histórico tem sido considerada uma bandeira nacional de Portugal, e também internacional, com um crescente aumento das preocupações com as questões climáticas vividas no interior dos edifícios antigos ou até naqueles mais recentes que trazem um interesse histórico e/ou cultural. Contudo, esta é uma área que ainda precisa de um forte impulso, apesar da reconhecida evolução observada com a adoção de normas europeias e o aparecimento crescente de estudos sobre o tema.

A abordagem ao estudo microclimático em edifícios históricos tem sofrido grande evolução, tendo seus paradigmas sofrido alterações significativas. Durante muitos anos a principal preocupação climática esteve ligada ao conforto térmico dos visitantes. Mais tarde, o paradigma começou a sofrer alterações, que motivaram que os valores fossem redirecionados para as necessidades de conservação dos materiais, com estudos laboratoriais que avançaram valores ideais de temperatura e umidade relativa para uma correta conservação de cada material (PAVLOGEORGATOS, 2003; CORGNATI; FILIPPI, 2010).

Durante a última década essas duas abordagens foram abandonadas, principalmente para edifícios de elevada inércia térmica que mantêm um clima histórico, sem exposições temporárias e sem a presença de sistemas de climatização. É possível observar que, para o primeiro caso, ao dar prevalência às necessidades humanas, podem-se criar condições adversas para os materiais e artefatos, visto que as necessidades de conforto térmico podem não ser as mesmas que garantam a conservação dos diversos materiais. $\mathrm{O}$ segundo redireciona a preocupação para os materiais, mas continua a ter lacunas graves, uma vez que os valores definidos são alcançados em laboratório e em materiais específicos, o que não recria as condições às quais os materiais possam ter se adaptado ao longo de sua vida, da mesma forma que não leva em conta o fato de alguns artefatos serem constituídos por camadas de materiais diferentes, com coeficientes de dilatação e tempos de relaxamento diferentes (BRATASZ, 2013).

Atualmente a abordagem que reúne maior consenso, tanto na Europa como na América do Norte, assenta em pressupostos diferentes. Assume-se que, quando determinado material ou artefato esteve por um longo período (mais de 1 ano) sob influência de determinadas condições, a adaptação motivará a ocorrência de fendas e deformações irreversíveis (EUROPEAN..., 2010), num processo caracterizado como aclimatação (BRATASZ, 2013). Alterar o microclima histórico para o qual determinado número de artefatos se aclimatou, mesmo que essa alteração seja para os valores tidos como ideais, pode provocar respostas catastróficas, visto o fato de os materiais poderem ter excedido sua capacidade de deformação, o que poderá conduzir, em último caso, a sua perda total. Paralelamente, apesar de apresentar ligeiras diferenças, surgiu o conceito de Proofed fluctuations, definido por Michalski (2007) como o clima vivido pelo artefato no passado como o objetivo para o futuro, assumindo que, se as maiores flutuações climáticas passadas não forem excedidas no futuro, o risco de novos danos mecânicos é extremamente baixo.

Pode-se notar que, para museus que recebem variadas exposições temporárias, por exemplo, os requisitos são diferentes, com a necessidade de utilizar os valores recomendados pelos proprietários da coleção ou, caso não existam, os valores tidos como ideais para os materiais presentes (CORGNATI; FILIPPI, 2010).

Apesar da normalização e dos estudos existentes, a bibliografia é ainda restrita, o que motiva a necessidade de testar as medidas avançadas internacionalmente e validar procedimentos de análise e correção para climas temperados. O aumento do número de estudos científicos referentes às necessidades higrotérmicas dos materiais contribui de forma clara para a definição de metodologias simples e objetivas, possíveis de aplicar até por técnicos menos experientes. O presente trabalho visa, acima de tudo, incrementar o conhecimento e aumentar o nível de exigência para os estudos e trabalhos de conservação, através do relato de um monitoramento de longo prazo de uma igreja do século XIII em Lisboa.

\section{Comportamento higrotérmico de edifícios de elevada inércia térmica}

Os edifícios históricos são normalmente caracterizados por paredes espessas e com grande capacidade de armazenar calor, o que se traduz numa grande eficácia no amortecimento e atraso da onda de calor proveniente do exterior. Esse comportamento contribui para um grande equilíbrio térmico do interior, alterado apenas por fatores externos, como sistemas de climatização, iluminação ou presença humana. 
Em igrejas, por exemplo, é comum verificar a presença de tetos em madeira sem isolamento térmico, o que leva a uma grande dependência das condições externas. Por outro lado, por norma, o piso térreo apresenta uma inércia térmica elevada, conferida pelo pavimento e terreno com os quais tem contato, resultando em maior constância de condições e elevada defasagem e amortecimento térmico (CAMUFFO, 1998).

A grande inércia térmica do pavimento e a reduzida resistência térmica da cobertura fazem com que a temperatura do pavimento seja mais alta do que a do teto no inverno, o que potencializa a presença de correntes de convecção. No verão ocorre o inverso, com o teto apresentando temperatura superior à do pavimento, o que resulta na estratificação do ar por temperaturas.

Devido à elevada espessura de seus elementos, que lhe conferem elevada inércia térmica, é comum que em edifícios desse tipo localizados em climas temperados, mas com diferenciação bem visível das estações do ano, como é o caso de Lisboa, a temperatura das paredes interiores apenas atinja o equilíbrio com a temperatura média do ar exterior na fase final do verão e do inverno, com os elementos absorvendo energia durante a estação de aquecimento e depois liberando-a durante a estação de resfriamento (HENRIQUES, 1994; CAMUFFO et al., 2004; SILVA, 2008).

A temperatura externa começa a subir geralmente na primavera, no entanto a temperatura das superfícies interiores não segue essa variação de imediato, permanecendo sob influência da estação precedente. Esse aumento de temperatura é muitas vezes acompanhado por aumento da humidade absoluta. Através da ventilação proporcionada pelas janelas, portas e outras aberturas, o ar exterior mais quente e úmido entra no edifício e resfria de forma gradual. Por consequência, sua umidade relativa aumenta, atingindo os valores mais elevados ao longo das superfícies das paredes. Esse aumento da umidade relativa ao longo das paredes pode conduzir a condensações superficiais, caso se ultrapasse o limite de saturação, contribuindo para a degradação do patrimônio e aumentando o risco de ataque por fungos em suas proximidades (HENRIQUES, 1994).

\section{Metodologia}

\section{Estudo de caso: Igreja de São Cristóvão em Lisboa}

A Igreja de São Cristóvão (monumento nacional de Portugal) situa-se na área da encosta do Castelo de São Jorge, em Lisboa. Esta cidade é caracterizada por um clima mediterrânico, com temperaturas amenas, dada a proximidade do oceano Atlântico, com cerca de 260 dias de sol por ano, temperatura e precipitação médias anuais de $17{ }^{\circ} \mathrm{C}$ e $725,8 \mathrm{~mm}$ respetivamente, e ventos predominantes de norte, segundo o Atlas Climático Ibérico (MINISTÉRIO..., 2011).

A localização da Igreja é conhecida desde o primeiro quarto do século XIII, quando foi construída em honra a Santa Maria de Alcamim, durante a ocupação árabe. Mais tarde, entre o final do século XIII e o início do século XIV, depois da reconquista cristã, passou a ser denominada Igreja de São Cristóvão. A Igreja permaneceu com sua configuração original até ao século XVI, quando sofreu danos graves durante um incêndio. Entre 1610 e 1672 aconteceram importantes obras de restauro, com a implementação de profundas alterações na estrutura original (MONSALVE, 2011).

O monumento apresenta-se como um dos poucos que se situam na zona central de Lisboa e que resistiram com poucos danos ao terramoto de 1755, apenas com a ocorrência de alguns estragos na torre sineira. Sua fachada (Figura 1.a) apresenta um estilo barroco-maneirista típico do século XVII, com um portal no centro e um nicho que suporta a imagem de São Cristóvão, ladeado por duas torres sineiras (MONSALVE, 2011).

$\mathrm{O}$ interior da Igreja (Figura 1b) caracteriza-se pela presença de uma nave retangular com $144 \mathrm{~m}^{2}$ de área e $13 \mathrm{~m}$ de altura máxima, com teto plano ao centro e paredes e tetos revestidos por painéis emoldurados com talha dourada e constituída por cinco nichos de altares, dois púlpitos, um coro e o altar-mor. A Igreja comporta ainda uma sacristia, a norte da nave central, e uma casa mortuária, a sul. Na sala principal há um coro elevado, com acesso pela casa mortuária, e um piso superior com varandas e janelas, que possibilitam a entrada de ar e radiação solar. Na Figura 1 é possível visualizar a Igreja em estudo - fachada frontal (Figura 1a) e interior (Figura 1b). Na Figura 2 é possível visualizar a planta do edifício.

No que diz respeito a sua estrutura, a Igreja de São Cristóvão apresenta paredes espessas e revestidas por pedra calcária, teto plano em madeira na nave principal, e teto em abóbada de berço constituída por alvenaria estucada no altar-mor. A cobertura, constituída por telha cerâmica e estrutura em madeira com desvão acessível, é caracterizada por um telhado de duas águas cobrindo a nave principal e de quatro águas para a sacristia, casa mortuária e altar-mor. 
Do ponto de vista artístico, é possível encontrar obras importantes do século XVII, com pinturas em madeira, estuque, pedra e tela, talha dourada, várias esculturas e azulejaria característica, tal como alguns livros de relevo (MONSALVE, 2011).

\section{Monitoramento do microclima exterior e interior do edifício}

O monitoramento microclimático foi conduzido com o intuito de compreender o comportamento do interior da igreja e a relação com o exterior. Para tal, foi utilizado um conjunto de sensores para a coleta de dados, tanto em medições automáticas como manuais. Os registros foram realizados entre novembro de 2011 e agosto de 2013, com leituras automáticas a cada 10 min (SILVA, 2012).

Figura 1 - Igreja de São Cristóvão, Lisboa

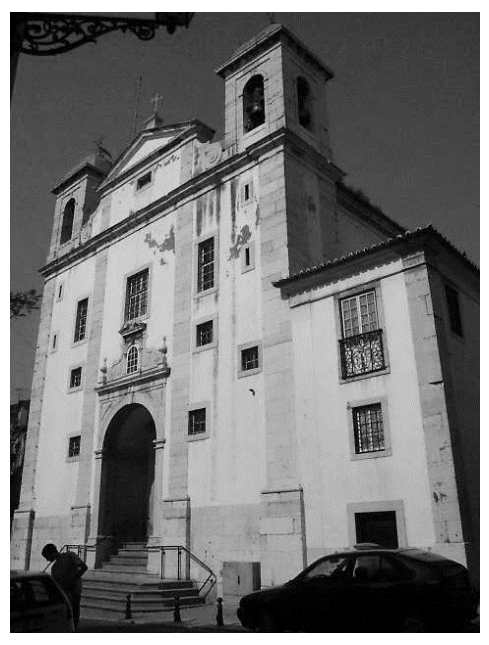

(a) Vista exterior

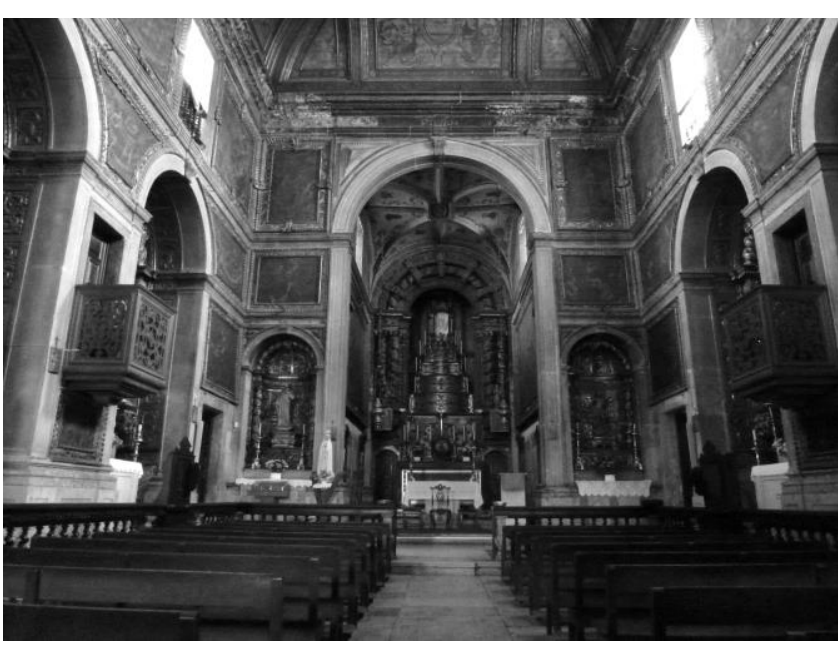

(b) Sala principal

Figura 2 - Planta da Igreja de São Cristóvão com a colocação dos sensores

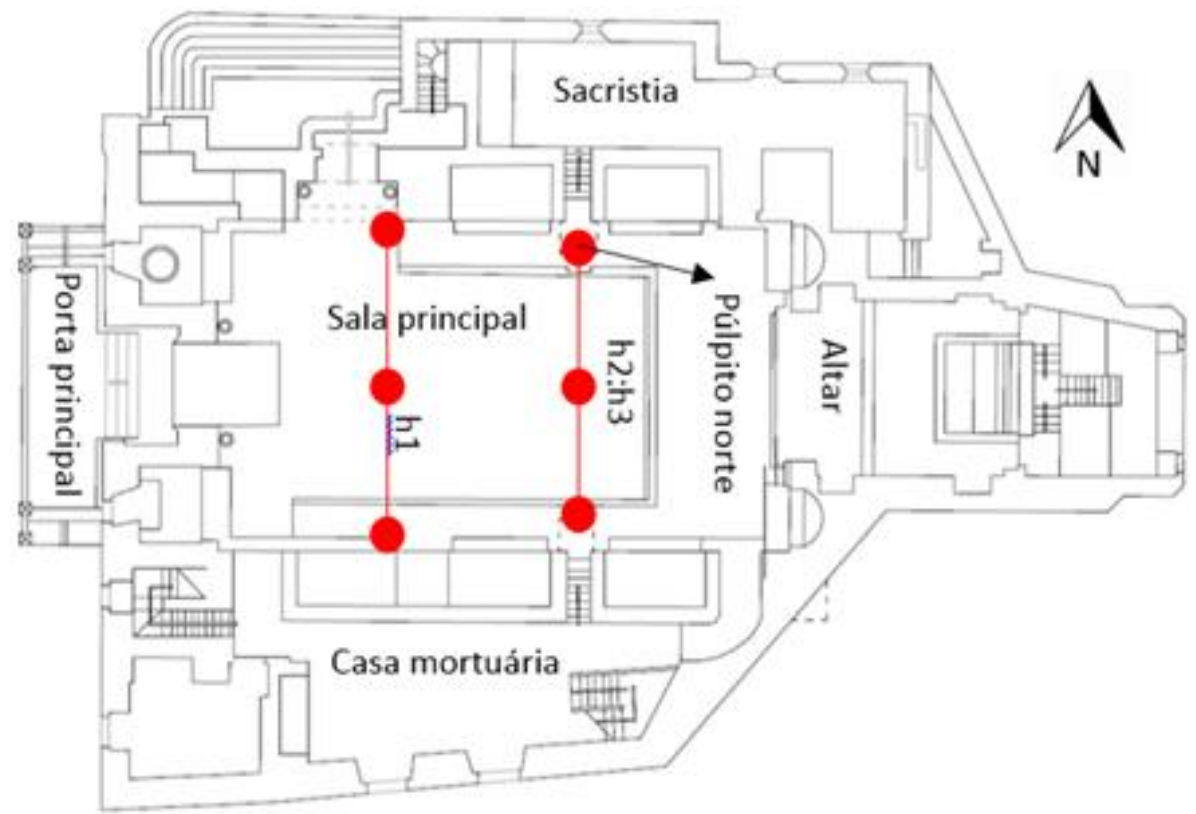

68 Silva, H. E.; Henriques, F. M. A. 


\section{Exterior}

A temperatura e a umidade relativa foram medidas de forma direta e automática, com o uso de um sensor portátil colocado na torre norte (H1 HOBO U12-13; incerteza: $\pm 0,35{ }^{\circ} \mathrm{C}$ para a temperatura, $\mathrm{e} \pm 2,5 \%$ para a umidade relativa) (SILVA; HENRIQUES, 2014). Para proteger o sensor das intempéries e da radiação solar, optouse por suspendê-lo num suporte de madeira com aberturas para o exterior, com revestimento térmico e um plástico impermeabilizante escuro.

\section{Interior}

No púlpito norte da nave principal a temperatura e a umidade relativa foram medidas diretamente com uma sonda (DeltaT RHT2nl), composta de um sensor de umidade relativa (incerteza: $\pm 2,5 \%$ ) e por um termistor (incerteza: $\pm 0,1^{\circ} \mathrm{C}$ ). Para garantir a comparabilidade entre aparelhos, colocou-se no mesmo local um sensor portátil (H2 - HOBO U1213; incerteza: $\pm 0,35{ }^{\circ} \mathrm{C}$ para a temperatura, e $\pm 2,5 \%$ para a umidade relativa) (SILVA; HENRIQUES, 2014).

No restante da sala a temperatura foi medida com termopares do tipo $\mathrm{T}$ (incerteza: $\pm 0,5^{\circ} \mathrm{C}$ ), e a umidade relativa foi calculada para todos os pontos, tomando os valores da sonda colocada no púlpito como referência e assumindo-se a concentração de vapor de água constante em toda a sala. O sistema de monitoramento da nave principal foi definido com o intuito de estudar a variação das condições em planta e obter, assim, a influência da exposição solar. Também foi objetivo estudar a estratificação do ar por temperaturas, definindo-se uma coluna vertical de sensores. Pretendeu-se ainda averiguar a possibilidade de ocorrerem condensações superficiais, com a instrumentação de uma superfície a norte do edifício. Optou-se por monitorizar a superfície a norte devido à menor exposição solar. É importante lembrar que Portugal está exposto a uma radiação solar predominante de sul. O sistema incluiu:

(a) 1 perfil vertical com 5 sensores, colocado no púlpito norte $(0,15 ; 1,50 ; 3,90 ; 7,50$ e $10 \mathrm{~m})$;

(b) 1 perfil horizontal (h1) com 3 sensores a 3,90 $\mathrm{m}$ de altura unindo os dois altares junto à porta principal;

(c) 2 perfis horizontais a 3,90 (h2) e 7,50 (h3) m de altura com 3 sensores cada unindo os dois púlpitos;

(d) 1 perfil horizontal com 3 sensores, colocado no altar-mor a uma altura de $5,30 \mathrm{~m}$; (e) 1 sensor no topo da porta de entrada para a sacristia, e outro no coro, a 5,30 m de altura; e

(f) 4 sensores de temperatura superficial no púlpito norte; 2 na parede e 2 no pavimento.

Realizaram-se ainda medições manuais esporádicas para validar o sistema automático.

Na Figura 2 é possível visualizar a planta da Igreja e a disposição dos sensores.

\section{Resultados}

\section{Caracterização do microclima interior e exterior da Igreja de São Cristóvão}

Este item tem o objetivo de caracterizar o comportamento climático da Igreja de São Cristóvão e analisar a influência das condições exteriores sob o interior, para justificar de forma concreta os conceitos teóricos já apresentados. Para tal, recorreu-se aos dados do interior da Igreja e à comparação com os ciclos sazonais do interior e exterior. Esses ciclos sazonais são definidos como a média móvel a 3 meses e pretendem mostrar as tendências do clima ao longo do ano, com a suavização dos ciclos de curta duração.

Os dados contínuos e os ciclos sazonais interiores e exteriores de temperatura e umidade relativa encontram-se nas Figuras $3 \mathrm{a}$ e $3 \mathrm{~b}$ respectivamente. É possível concluir que os ciclos sazonais interiores são mais tênues que os exteriores, observando-se uma variação interior de temperatura entre os $14,1{ }^{\circ} \mathrm{C}$ e $24,2{ }^{\circ} \mathrm{C}$, e de umidade relativa entre os $59,2 \%$ e os $70,8 \%$. Nos ciclos sazonais exteriores verificam-se variações superiores, com a temperatura variando entre os $11,7^{\circ} \mathrm{C}$ e os $24,5^{\circ} \mathrm{C}$, e a umidade relativa entre os $57,2 \%$ e os $82,5 \%$.

A influência exterior é evidente, principalmente entre a primavera e o outono, devido à maior exposição solar existente no verão, contudo o efeito da inércia térmica é claro. $\mathrm{O}$ ciclo interior encontra-se amortecido e desfasado do exterior. Veja-se que o ciclo exterior começa a aumentar a partir de janeiro, enquanto o interior ainda permanece sob influência do inverno e apenas experimenta uma subida abrupta com aproximação ao exterior em março. No verão este efeito é menos pronunciado, dadas a forte radiação solar e a fraca resistência térmica da cobertura, mas ainda assim é possível verificar um atraso considerável em resultado do início da tendência descendente. 
Figura 3 - Comparação entre os dados contínuos interiores e os ciclos sazonais interiores e exteriores

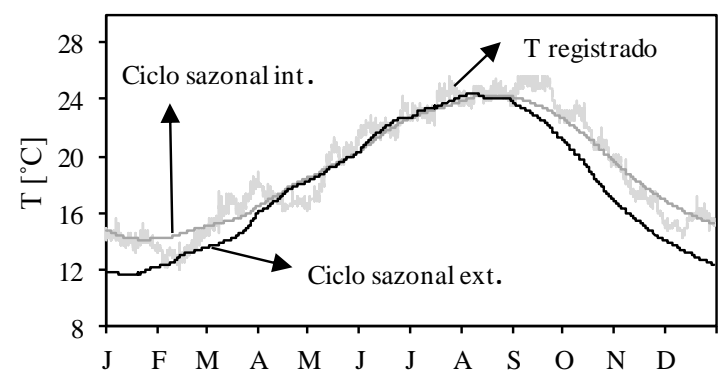

(a) Temperatura

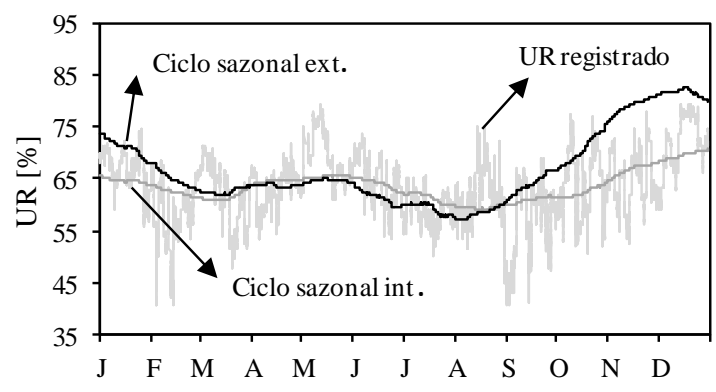

(b) Umidade relativa

\section{Classificação microclimática e definição de limites sustentáveis}

Como já mencionado, muitas vezes existe a tendência de se analisar o microclima de um edifício com base em valores absolutos, tidos como ideais para a conservação dos materiais e definidos laboratorialmente, ou pela experiência em outros edifícios, como aqueles encontrados na norma italiana UNI 10829 (ENTE..., 1999). Não se pretende desacreditar esses valores, mas sim evidenciar que nem sempre podem ser assumidos com demasiado rigor, pois em edifícios antigos, sem exposições temporárias e sem sistemas de controle ambiental, onde muitas vezes os ambientes permanecem estáveis durante séculos, os artefatos podem ter sofrido alterações e reajustes de modo a se adaptarem ao clima. Posto isso, pode-se concluir facilmente que os valores ideais para materiais novos ou artefatos compostos de vários materiais podem não ser os corretos para a manutenção dos artefatos antigos (MARTENS; SCHELLEN, 2010). Contudo, esses valores tabelados continuam a ser bastante úteis, principalmente para edifícios com exposições temporárias ou quando se pretende atingir um clima-alvo para determinado conjunto de materiais.

Nas últimas décadas vários especialistas têm-se pronunciado sobre a análise microclimática e definição de valores ideais em edifícios de importância histórica e cultural, como museus e igrejas, sendo praticamente unânime a dificuldade em limitar o clima dos referidos edifícios a valores ideais, ou, pelo menos, a um conjunto de valores universais, tendo-se evoluído para uma abordagem distinta e mais abrangente, em que se considera que pequenos desvios em curtos períodos não são suficientes para criar danos aos materiais (BRATASZ; CAMUFFO; KOZLOWSKI, 2007; MARTENS; SCHELLEN, 2010).

Tem-se verificado também uma crescente procura por sistemas de climatização para controlar ambientes e corrigir condições danosas. Essa solução pode aumentar os riscos de degradação e carece de grande conhecimento do local e cuidado em sua prescrição; apesar de ser muito utilizada em países com climas frios do centro e norte da Europa, é do interesse comum estudar sua eficácia em climas mais temperados.

A envolvente exterior, como nos edifícios comuns, assume aqui um papel preponderante, considerando-se que dificilmente se podem controlar as condições interiores sem ter em conta a camada exterior do edifício, onde muitas vezes as propriedades térmicas e impermeabilizações estão comprometidas.

Neste estudo, como ponto de partida, classificou-se de forma clara o microclima interior da Igreja, com o objetivo de verificar se está de acordo com as necessidades dos artefatos que abriga, seguindo-se de uma análise mais cuidada para validar qualquer tipo de alteração.

Apesar de existirem várias metodologias, optou-se por utilizar uma classificação para museus, galerias, arquivos e livrarias desenvolvida pela American Society of Heating, Refrigeration and Air Conditioning Engineers, inicialmente utilizada na América do Norte e hoje em dia também em alguns outros lugares do mundo. Essa especificação define várias classes climáticas, de modo a limitar os riscos de degradação dos materiais, com foco nos danos mecânico, biológico e químico (AMERICAN..., 2007).

Os dados fornecidos por essa classificação permitem definir, por exemplo, num edifício com várias salas, onde se deve colocar cada coleção ou de que forma se deve corrigir o clima interior. Apesar de a especificação procurar classificar ambientes, também pode ser utilizada para definir intervalos ideais.

Na Tabela 1 encontram-se a definição do método de classificação e as várias classes existentes, de forma resumida. 
Essa classificação divide-se em várias classes, e a mais exigente é a AA, que limita de forma importante as variações tanto de temperatura como de umidade relativa. A menos exigente é a classe $\mathrm{D}$, que limita apenas o intervalo superior de umidade relativa, de modo a reduzir o risco de ataque biológico.

Para aplicar esse método, continua a ser necessária uma análise estatística, mesmo que no final sejam obtidas classes em que são descritos de forma clara os riscos associados a cada uma. Esta análise estatística necessita de alguns cuidados para garantir sua qualidade, fazendo uma procura por valores atípicos e sua correção, com a exclusão dos valores abaixo do $0,1^{\circ}$ percentil e acima do $99,1^{\circ}$ percentil, tanto para a temperatura como para a umidade relativa.

Como valores "alvo" utilizaram-se a temperatura média anual, que a especificação limita a valores entre os $15^{\circ} \mathrm{C}$ e os $25^{\circ} \mathrm{C}$; e a média anual de umidade relativa (permitida para edifícios onde é possível que os artefatos já tenham sofrido uma forte aclimatação) (AMERICAN..., 2007).

Com os dados descritos na Tabela 1 , facilmente se caracteriza um ambiente, bastando saber que o ciclo sazonal é definido como uma média móvel a 3 meses (91 dias), calculada de acordo com a Equação 1, e que as variações de curta duração são aquelas que ocorrem num período inferior ao ciclo sazonal, aqui definidas como a subtração entre os valores registrados e a média móvel (MARTENS, 2012).

$X_{\text {móvel }, i}=\frac{1}{n} \cdot \sum_{a=i-0.5 \cdot n}^{i+0.5 \cdot n} X_{a}$

Eq. 1

Em que:

$X_{\text {móvel: }}$ ciclo sazonal (média móvel a 91 dias) de $\mathrm{T}$ $\left({ }^{\circ} \mathrm{C}\right)$ ou UR $(\%)$;

\section{$X: \mathrm{T}\left({ }^{\circ} \mathrm{C}\right)$ ou UR $(\%)$;}

$n$ : número de pontos no intervalo [91 (dias) x 24

(h) x 6 (intervalos de $10 \mathrm{~min} / \mathrm{h})]$; e

$i$ : ponto corrente dentro do intervalo.

Tabela 1 - Classes climáticas para museus, galerias, arquivos e livrarias segundo a ASHRAE

\begin{tabular}{|c|c|c|c|c|}
\hline $\begin{array}{c}\text { Fonte ou } \\
\text { instituição } \\
\text { emissora da } \\
\text { especificação }\end{array}$ & Valor alvo & $\begin{array}{l}\text { Ciclos } \\
\text { sazonais }\end{array}$ & $\begin{array}{l}\text { Variações de } \\
\text { curta duração }\end{array}$ & Observações \\
\hline \multirow{6}{*}{ ASHRAE } & \multirow{6}{*}{$\begin{array}{c}\mathrm{T}_{\text {média anual }} \\
15^{\circ} \mathrm{C} \mathrm{a} \\
25^{\circ} \mathrm{C} ; \\
\text { UR: } 50 \% \text { ou } \\
\text { a média } \\
\text { anual para } \\
\text { exposições } \\
\text { permanentes }\end{array}$} & $\begin{array}{l}\mathrm{T}: \pm 5^{\circ} \mathrm{C} ; \\
\text { UR: } \mathrm{SV}^{(1)}\end{array}$ & $\begin{array}{l}\mathrm{T}: \pm 2{ }^{\circ} \mathrm{C} \\
\mathrm{UR}: \pm 5 \%\end{array}$ & $\begin{array}{c}\text { Classe AA - Sem risco de danos } \\
\text { para a maioria dos artefatos e } \\
\text { pinturas } \\
\end{array}$ \\
\hline & & $\begin{array}{c}\text { As: } \mathrm{T}:+5^{\circ} \mathrm{C} \\
-10^{\circ} \mathrm{C} \\
\text { UR: } \pm 10 \% \\
\end{array}$ & $\begin{array}{l}\mathrm{T}: \pm 2{ }^{\circ} \mathrm{C} ; \\
\mathrm{UR}: \pm 5 \%\end{array}$ & \multirow{2}{*}{$\begin{array}{l}\text { Classe A - Risco reduzido de danos } \\
\text { mecânicos para os artefatos de alta } \\
\text { vulnerabilidade; nenhum risco } \\
\text { mecânico para a maioria dos } \\
\text { artefatos e pinturas }\end{array}$} \\
\hline & & $\begin{array}{c}\text { A: } \mathrm{T}:+5^{\circ} \mathrm{C} \\
-10^{\circ} \mathrm{C} \\
\text { UR: } \mathrm{SV}^{(1)} \\
\end{array}$ & $\begin{array}{l}\mathrm{T}: \pm 2{ }^{\circ} \mathrm{C} \\
\text { UR: } \pm 10 \%\end{array}$ & \\
\hline & & $\begin{array}{l}\mathrm{T}:+10^{\circ} \mathrm{C} \\
<30^{\circ} \mathrm{C} \\
\mathrm{UR}: \pm 10 \%\end{array}$ & $\begin{array}{l}\mathrm{T}: \pm 5^{\circ} \mathrm{C} \\
\text { UR: } \pm 10 \%\end{array}$ & $\begin{array}{l}\text { Classe B - Risco moderado de } \\
\text { danos mecânicos para os artefatos } \\
\text { de alta vulnerabilidade; pequeno } \\
\text { risco para a maioria das pinturas }\end{array}$ \\
\hline & & \multicolumn{2}{|c|}{$\begin{array}{l}\text { T raramente }>30^{\circ} \mathrm{C} \\
\text { Geralmente }<25{ }^{\circ} \mathrm{C} \\
\text { UR: } 25 \% \text { a } 75 \%\end{array}$} & $\begin{array}{c}\text { Classe C - Alto risco de danos } \\
\text { mecânicos nos artefatos de alta } \\
\text { vulnerabilidade; risco moderado } \\
\text { para a maioria das pinturas }\end{array}$ \\
\hline & & \multicolumn{2}{|c|}{ UR: $<75 \%$} & $\begin{array}{l}\text { Classe D - Alto risco de danos } \\
\text { mecânicos imediatos ou } \\
\text { cumulativos para a maioria dos } \\
\text { artefatos e pinturas }\end{array}$ \\
\hline
\end{tabular}

Fonte: American Society of Heating, Refrigeration and Air-Conditioning Engineers (2007) e Bratasz (2013).

Nota: variações de umidade relativa (UR) e temperatura ( $T$ ).

Legenda:

${ }^{(1)} \mathrm{SV}$ : sem variação; e

${ }^{(2)}$ SE: sem especificação. 
$\mathrm{Na}$ Figura 4 apresenta-se o processo de classificação ASHRAE para a classe B, o que possibilita uma fácil compreensão do método. Iniciou-se o processo com os valores registrados, com a exclusão dos valores extremos (a), definiram-se os ciclos sazonais com base numa média móvel a 3 meses, e calculou-se a média anual (b). Em seguida, de acordo com a Tabela 1, verificou-se qual o intervalo admissível para as variações sazonais, e adaptou-se a média móvel (c); por fim, definiram-se os intervalos admissíveis, com a soma das gamas admissíveis para as variações de curta duração à média móvel. Para classificar o ambiente verificou-se o número de leituras presentes no interior do intervalo definido, traduzidas sob a forma de percentagem.

Essa classificação apresenta algumas limitações, pois assume que um clima apenas pertence a determinada classe se $100 \%$ de seus valores estiverem no interior do respetivo intervalo. Contudo, como tem sido corrente em vários estudos, optou-se não por definir a classe exata, mas sim pela análise completa, com a verificação da percentagem de valores que cumprem cada classe, o que oferece uma base sólida para possíveis alterações (MARTENS, 2012).
Com a análise da Figura 5 e da Tabela 2 é possível verificar a distribuição percentual do clima interior da Igreja pelas várias classes.

Ao analisar individualmente as variáveis, verificase, numa primeira instância, que não existem problemas quanto à temperatura, pois para a classe AA (a mais exigente) o edifício começa a cumprir os requisitos em $98 \%$ dos casos. Classificando o edifício apenas quanto à temperatura, este obteria a classificação B, sem necessidade de qualquer alteração.

Quanto à umidade relativa, verifica-se menor estabilidade, com nenhuma das classes a cobrir a totalidade dos valores registrados. Contudo, verifica-se que a partir da classe A os limites são cumpridos em $87,9 \%$ dos casos, o que mostra a necessidade de fazer uma análise mais cuidada, para observar a duração dos períodos de não cumprimento e avaliar sua casualidade.

Fazendo uma análise global, ou seja, considerando a temperatura e a umidade relativa simultaneamente (coluna central da Figura 5 e Tabela 2), constata-se, como já havia sido descrito, que a umidade relativa assume o papel preponderante na classificação deste caso em particular.

Figura 4 - Classificação do microclima interior com base na classe B ASHRAE: (a) temperatura e umidade relativas reais; (b) média anual (linha horizontal) e média móvel; (c) média móvel com os limites impostos pela classe B aos ciclos sazonais; e (d) limites sustentáveis segundo a classe B, somando as variações de curta duração à média móvel
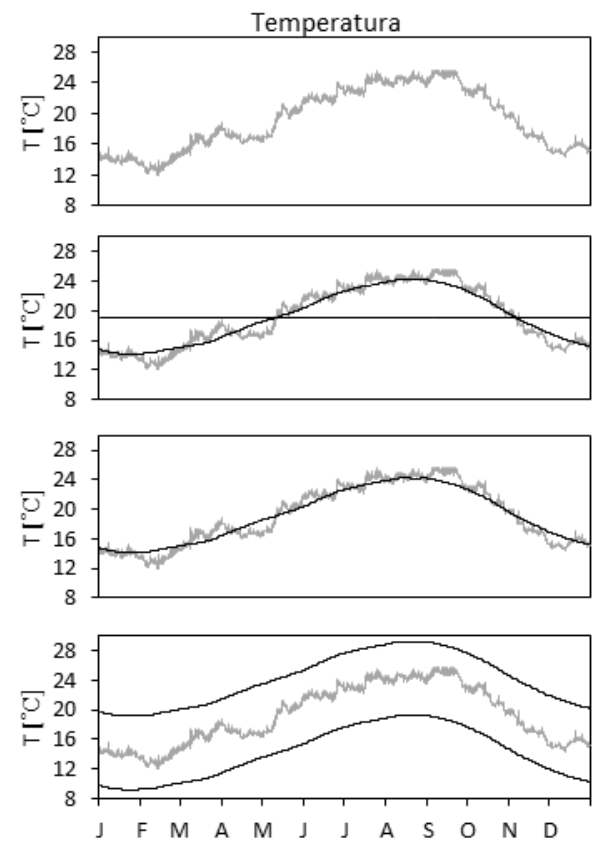

(a)

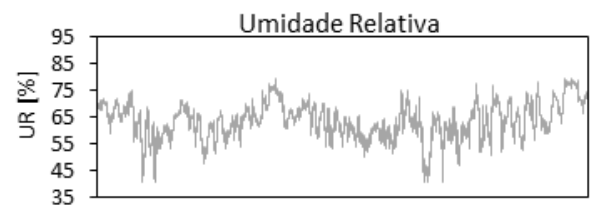

(b)
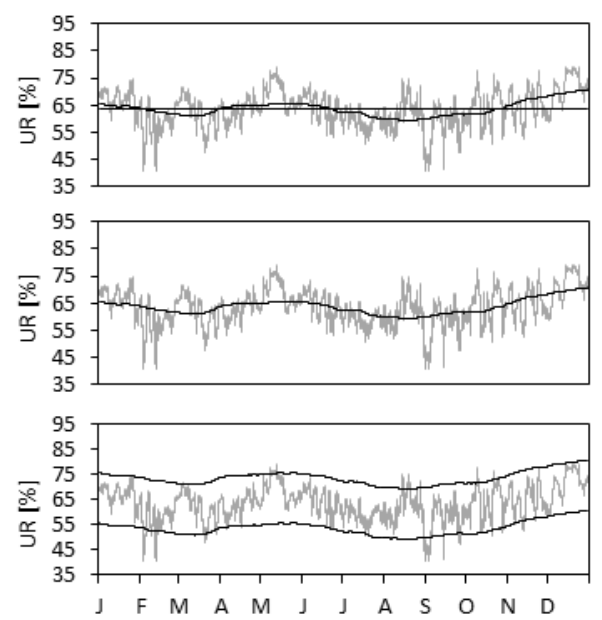

72 Silva, H. E.; Henriques, F. M. A. 
Figura 5 - Classificação do ambiente interior da Igreja de São Cristóvão com base nas classes ASHRAE para os dados obtidos durante 1 ano - as percentagens da esquerda correspondem aos valores incluídos dentro do intervalo sustentável de temperatura, enquanto as da direita correspondem à umidade relativa, e as centrais, à intersecção da temperatura e umidade relativa

$98,0 \%$

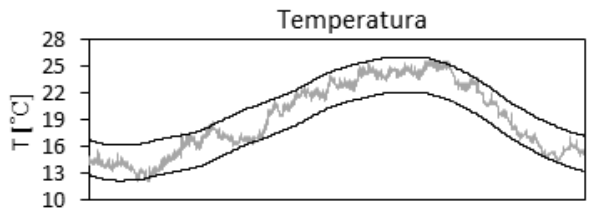

AA $54,8 \%$

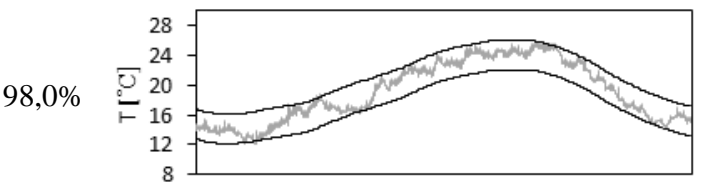
8

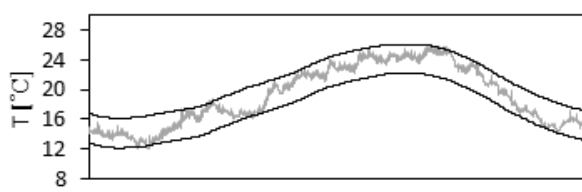

$98,0 \%$

$100 \%$

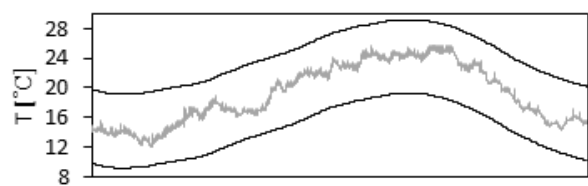

$100 \%$

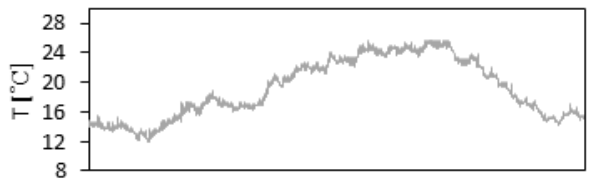

$100 \%$

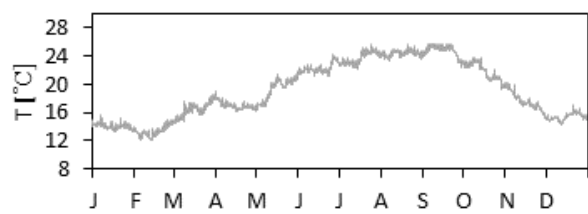

As
$62,2 \%$

$92,5 \%$ $95,0 \%$

$\mathrm{D}$

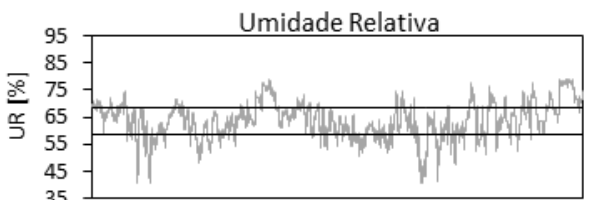

$55,8 \%$

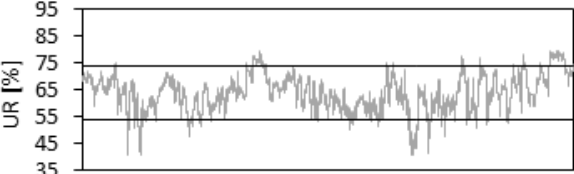

$87,9 \%$

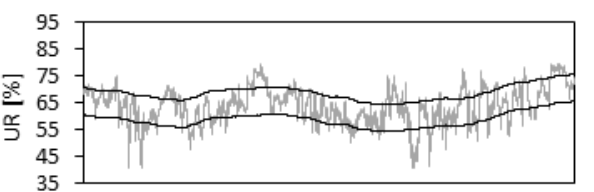

$63,2 \%$

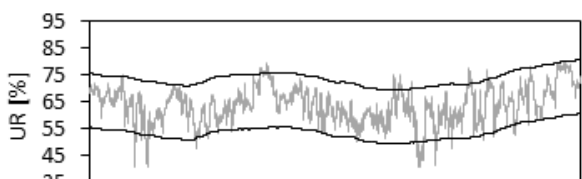

$92,5 \%$

产 65

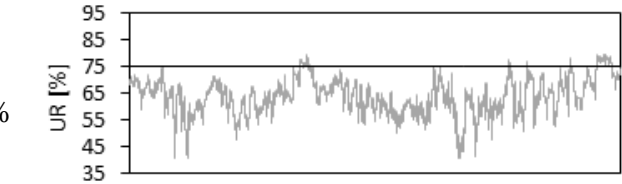

$95,0 \%$

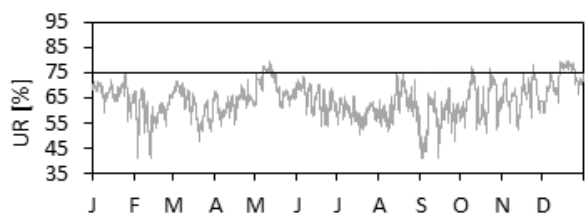

Tabela 2 - Classificação do interior da Igreja de São Cristóvão de acordo com as classes ASHRAE

\begin{tabular}{c|c|c|c|c|c|c}
\hline Posição & AA & A & As & B & C & D \\
\hline $\begin{array}{c}\text { Nave Principal - Igreja de } \\
\text { São Cristóvão }\end{array}$ & $54,8 \%$ & $86,5 \%$ & $62,2 \%$ & $92,5 \%$ & $95 \%$ & $95 \%$ \\
\hline
\end{tabular}

\section{Análise de resultados e discussão de soluções}

Com a definição da classe B como objetivo, foi possível alcançar os resultados presentes na Figura 6 , onde se podem observar os períodos temporais em que os limites sustentáveis não foram cumpridos. Verificou-se não cumprimento em vários momentos, que se traduziu num total acumulado de 16 dias acima do limite, e 11 abaixo. Contudo, é possível verificar que nos casos mais graves, acima e abaixo do intervalo alvo respectivamente, o limite apenas foi ultrapassado de forma contínua em 5 dias e 19 horas e em 5 dias e 2 horas. Apesar de não ser um fato desejável, é sabido que muitos materiais têm tempos de resposta elevados e muitas vezes superiores a 1 dia, considerando que o clima interior da Igreja não constitui risco elevado para a conservação dos materiais que estão lá alocados há longos anos. Contudo, optou-se por analisar a situação de forma mais cuidada, de modo a validar possíveis alterações e sua eficácia. Existem várias soluções corretivas que podem ser implementadas, com destaque ao controle de temperatura ou umidade absoluta, ventilação e alteração da envolvente exterior. É necessário analisar as soluções e o risco inerente quando comparadas com o clima existente. 
Na Figura 7 é possível encontrar a evolução da umidade relativa, umidade absoluta e temperatura, tanto para o interior como para o exterior. Para facilitar a percepção dos dados optou-se por uma representação por meio de uma média móvel de 30 dias.

Observa-se facilmente a forte relação entre interior e exterior, principalmente para a umidade absoluta, de onde se depreende que a alteração da ventilação do edifício não representa uma medida significativa, pois os valores interiores não são significativamente superiores aos exteriores. Quanto à temperatura e à umidade relativa, verifica-se também uma forte dependência do interior em relação ao exterior, mas com grau inferior.

Ao relacionar a umidade relativa interior com a temperatura interior e a umidade absoluta interior e exterior, não é possível determinar correlações fortes, contudo se conclui que esta está mais fortemente relacionada com a temperatura interior, onde pode ser possível a implementação de sistemas de umedecimento do ar.

Este fato é fortalecido com a análise da umidade absoluta em conjunto com a temperatura. Nota-se que os valores sazonais mais elevados de umidade absoluta ocorrem no período de verão, e os mais baixos, no período de inverno, o que deveria conduzir a umidades relativas máximas no verão e mínimas no inverno. Não é o que se verifica, pois a temperatura segue um comportamento semelhante e assume uma influência preponderante.

Sendo assim, apesar de inicialmente ter sido colocado que a temperatura por si só não constitui qualquer risco, é possível concluir que qualquer alteração deverá ser feita com o controle da temperatura interior, como meio de controle da umidade relativa. Esta medida poderá ser implementada com a correção térmica do edifício, principalmente na cobertura, com a colocação de isolamento térmico, o que conduzirá a menores flutuações de temperatura, com seu aumento no inverno e diminuição no verão, e consequentemente maior estabilidade em termos de umidade relativa, com ciclos menores e valores mais próximos de média anual. A Figura 8 permite concluir a variação da temperatura e umidade relativa em função da altura. No inverno (Figura 8a), quando a temperatura exterior é mais baixa e o pavimento ainda detém calor armazenado, as temperaturas mais próximas da cobertura apresentam valores menores. Por sua vez, no verão (Figura 8b), quando a radiação solar atinge valores mais elevados, a situação inverte-se. Apesar da grande inércia térmica do edifício, devido à falta de isolamento térmico na cobertura, o ambiente interior varia sazonalmente em função das condições exteriores.

Apesar disso, volta-se a destacar que o microclima em questão não constitui perigo de acréscimo de degradação para os materiais e que estas possíveis alterações não apresentam urgência de aplicação.

Desaconselha-se veementemente o recurso a qualquer tipo de sistema de controle mecânico, evitando a inserção de fatores potencialmente desestabilizadores num ambiente por si só estável. É importante notar que esses sistemas, quando não são de funcionamento contínuo, contribuem para amplificar os ciclos diários. Um sistema de controle está também sujeito a possíveis avarias, e a definição do ambiente ótimo nem sempre é fácil, já que exige, numa primeira fase, um estudo cuidadoso do ambiente histórico e depois o monitoramento contínuo em caso de se aplicar o sistema, de modo a controlar seu funcionamento.

\section{Figura 6 - Períodos em que o intervalo sustentável definido pela classe B - ASHRAE não é cumprido}

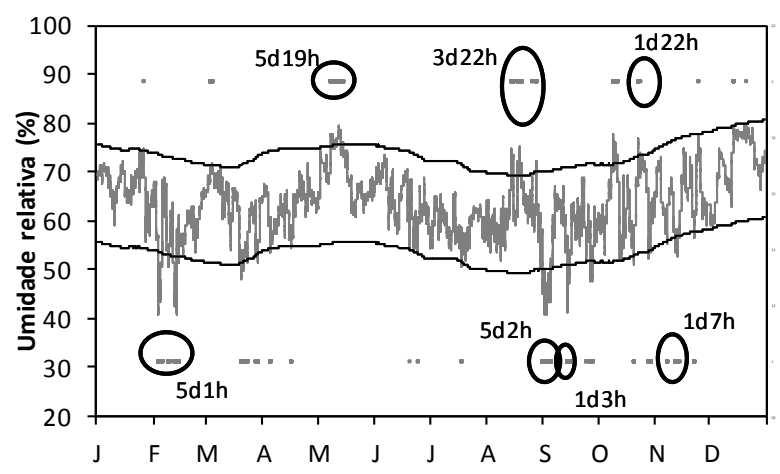

74 Silva, H. E.; Henriques, F. M. A. 
Figura 7 - Relação entre umidade relativa (UR), temperatura (T) e umidade absoluta (UA) no interior (linhas cinzentas) e exterior (linhas pretas)

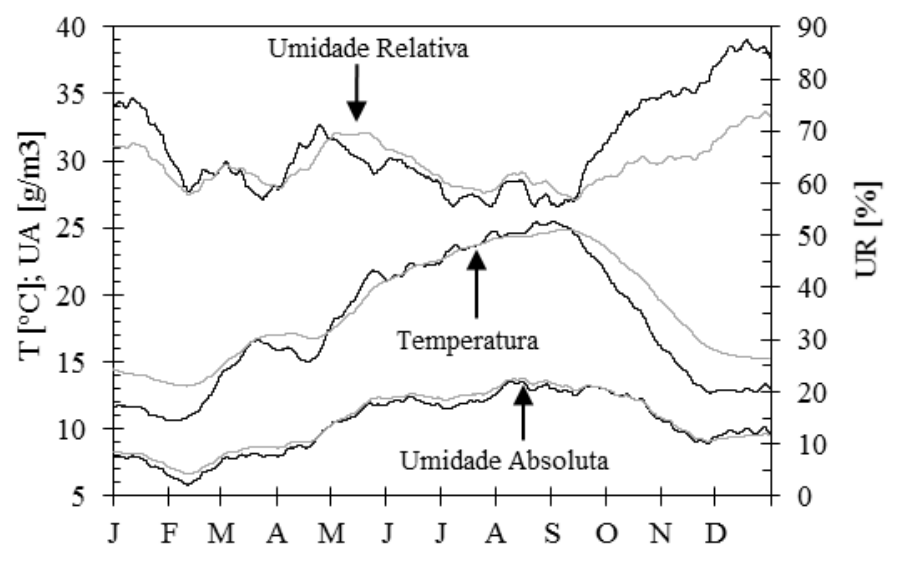

Figura 8 - Perfil vertical de temperatura e umidade relativa do ar no interior da Igreja a 0,15 m e $10 \mathrm{~m}$

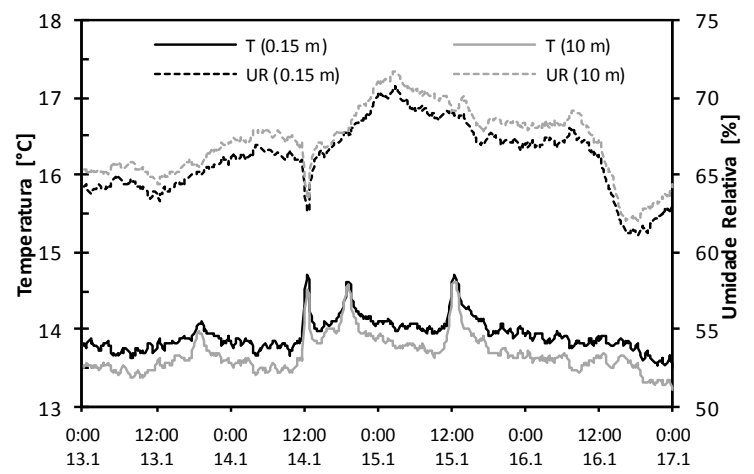

(a) Inverno (janeiro)

\section{Conclusões}

Este estudo permitiu aumentar o conhecimento do comportamento de edifícios de elevada inércia térmica em climas temperados, com a análise de um caso prático e a implementação de um sistema de monitorização exaustivo num monumento nacional de Portugal.

Foi possível avaliar o equilíbrio microclimático nesse tipo de edifício, que, sem a utilização de sistemas de climatização, consegue manter valores estáveis de acordo com as exigências dos materiais, principalmente daqueles que passaram longos períodos sob sua influência. Concluiu-se que, apesar da grande mais-valia que outros estudos possam acrescentar, principalmente aqueles realizados em climas frios, onde mais recorrentemente é dada uma importância maior a este tema, eles não devem ser implementados de forma direta em regiões abrangidas por climas diversos.

É necessário estudar cuidadosamente e de forma individual cada caso, ou pelo menos tomar como guia casos semelhantes. A implementação de

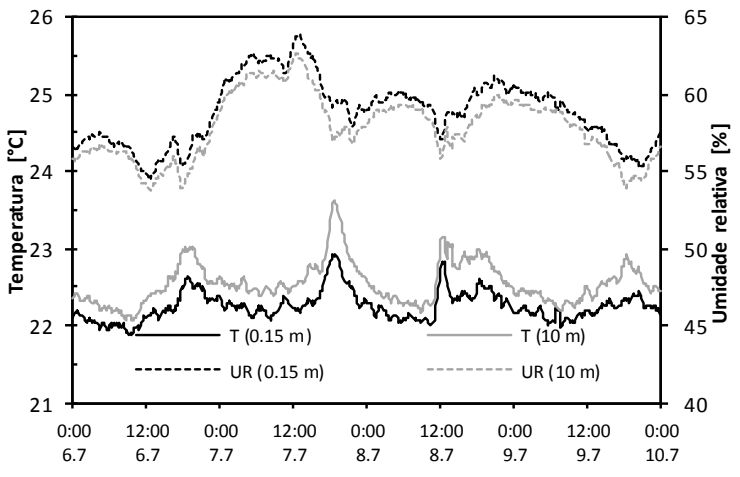

(b) Verão (julho)

sistemas de climatização, amplamente utilizados no centro e norte da Europa, dadas as baixas temperaturas, constitui sempre um fator desestabilizador, e no caso de um clima temperado pode ter um papel inverso ao desejado $\mathrm{e}$ incrementar o risco de degradação dos materiais, caso simulem condições diferentes daquelas para as quais os materiais se aclimataram.

Assim, conclui-se que, para climas semelhantes, muitas vezes não existe a necessidade de alterar o microclima interior dos edifícios, ou, quando essa necessidade existir, as correções podem em muitos casos ser colocadas em prática por meio de alterações à envolvente exterior, corrigindo a temperatura de forma direta, e a umidade relativa de forma indireta. Contudo, essa solução nem sempre pode ser aplicada, e cada caso carece de um estudo cuidadoso, pois o problema pode não estar relacionado com a temperatura. Nota-se que pode ser preponderante a correção da umidade absoluta interior, o que pode ser realizado com a correção da ventilação do edifício para casos em que a umidade absoluta exterior seja inferior, ou, no caso contrário, através do umedecimento do ar. 
Por fim concluiu-se que qualquer alteração que seja feita deverá sempre procurar reduzir os ciclos diários de temperatura e umidade relativa, contribuir para a estabilidade interna e introduzir o menor número possível de fatores desestabilizadores, tais como iluminação e/ou sistemas de aquecimento não adequados.

\section{Referências}

AMERICAN SOCIETY OF HEATING, REFRIGERATION AND AIR-CONDITIONING ENGINEERS. ASHRAE Handbook HVAC

Applications: Museums, galleries, archives and libraries. Atlanta, 2007. cap. 21.

BRATASZ, L. Allowable Microclimatic Variations in Museums and Historic Buildings: reviewing the guidelines. In: CLIMATE FOR COLLECTIONS: STANDARDS AND UNCERTAINTIES, Munich, 2012. Proceedings... Munich, 2013.

BRATASZ, L.; CAMUFFO, D.; KOZŁOWSKI, R. Target Microclimate For Preservation Derived From Past Indoor Conditions. In: CONTRIBUTIONS TO THE MUSEUM MICROCLIMATES CONFERENCE, COPENHAGEN, Copenhagen, 2007.

Proceedings... Denmark, 2007.

CAMUFFO, D. et al. The Impact of Heating, Lighting and People in Re-Using Historical Buildings: a case study. Journal of Cultural Heritage, v. 5, n. 4, p. 409-416, oct./dec. 2004.

CAMUFFO, D. Microclimate For Cultural Heritage. Amsterdam: Elsevier Science, 1998.

CORGNATI, S. P.; FILIPPI, M. Assessment of Thermo-Hygrometric Quality in Museums: method and in-field application to the "Duccio di Buoninsegna" exhibition at Santa Maria della Scala (Siena, Italy). Journal of Cultural Heritage, v. 11, n. 3, p. 345-349, july/set. 2010.

ENTE NAZIONALE ITALIANO DI UNIFICAZIONE. UNI 10829: beni di interesse storico artístico: condizioni ambientali di conservazione. Misurazione ed analisi. Milão, 1999.

\section{EUROPEAN COMMITTEE FOR}

STANDARDISATION. EN 15757: conservation of cultural property: specifications for temperature and relative humidity to limit climate-induced mechanical damage in organic hygroscopic materials. Bruxelas, 2010.

HENRIQUES, F. M. A. Humidade [sic] em Paredes. Lisboa: Laboratório Nacional de Engenharia Civil, 1994.
MARTENS, M. Climate Risk Assessment in Museums. Eindhoven, 2012. Tese (Doutorado em Engenharia Civil) - Eindhoven University of Technology, Eindhoven, Netherlands, 2012.

MARTENS, M. H. J.; SCHELLEN, H. L. A Sound Indoor Climate For a Museum in a Monumental Building. In: THERMAL PERFORMANCE OF THE BUILDING EXTERIOR ENVELOPES OF WHOLE BUILDINGS, Florida, 2010. Proceedings... Florida, 2010.

MICHALSKI S. The Ideal Climate, Risk Management, the ASHRAE Chapter, Proofed Fluctuations, and Towards a Full Risk Analysis Model. In: EXPERTS ROUNDTABLE ON SUSTAINABLE CLIMATE MANAGEMENT STRATEGIES, Los Angeles, 2007. Proceedings... Los Angeles, 2007.

MINISTÉRIO DE MEDIO AMBIENTE Y MEDIO RURAL Y MARINO E INSTITUTO DE METEOROLOGIA DE PORTUGAL. Atlas Climático Ibérico: temperatura do ar e precipitação (1971-2000). Lisboa, 2011.

MONSALVE, M. Igreja Paroquial de São Cristóvão: relatório de inventário e diagnóstio. Lisboa: Igreja Paroquial de São Cristóvão, 2011.

PAVLOGEORGATOS, G. Environmental Parameters in Museums. Building and Environment, v. 38, n. 12, p. 1457-1462, dec. 2003.

SILVA, H. E. Avaliação do Clima Interior de Uma Igreja em Lisboa. Monte de Caparica, 2012. Tese (Mestrado em Engenharia Civil) - Faculdade de Ciências e Tecnologia, Universidade Nova de Lisboa, Monte de Caparica, 2012.

SILVA, H. E.; HENRIQUES, F. M. A. Microclimatic Analysis of Historic Buildings: a new methodology for temperate climates.

Building and Environment, v. 82, p. 381-387, dec. 2014.

SILVA, T. A. L. Estudo Experimental do Comportamento Higrotérmico de Igrejas. Porto, 2008. Tese (Mestre em Engenharia Civil) Faculdade de Engenharia, Universidade do Porto, Porto, 2008.

\section{Agradecimentos}

Este estudo foi cofinanciado pelo projeto PTDC/ECM-COM/3080/2012. Os autores agradecem à Paróquia de São Cristóvão, nas pessoas do Padre Edgar Clara e do Sr. Luís Nobre. Os autores agradecem ainda a importante ajuda do Eng. Técnico Vitor Silva. 


\section{Hugo Entradas Silva}

Departamento de Engenharia Civil, Faculdade de Ciências e Tecnologia | Universidade Nova de Lisboa | Quinta da Torre | Caparica Portugal | 2829-516 | Tel.: +(351) 21294-8580 | E-mail: h.silva@campus.fct.unl.pt

\section{Fernando Manuel Anjos Hemriques}

Departamento de Engenharia Civil, Faculdade de Ciências e Tecnologia | Universidade Nova de Lisboa | E-mail: fh@fct.unl.pt

Revista Ambiente Construído

Associação Nacional de Tecnologia do Ambiente Construído

Av. Osvaldo Aranha, $99-3^{\circ}$ andar, Centro

Porto Alegre - RS - Brasil

CEP $90035-190$

Telefone: +55 (51) 3308-4084

Fax: +55 (51) 3308-4054

www.seer.ufrgs.br/ambienteconstruido

E-mail: ambienteconstruido@ufrgs.br 